\title{
A Research Note on
}

Multinationality and Firm Performance: Nonparametric Frontier Analysis Kevin Grant ${ }^{1 *}$, Roman Matousek², Martin Meyer², Nickolaos G. Tzeremes ${ }^{3}$

1* University of Dundee School of Business, University of Dundee, Dundee, DD1 4HN, *Corresponding author's e-mail address:K.Grant@dundee.ac.uk

2 Kent Business School, University of Kent, Canterbury, CT2 7PE, UK. 3 Department of Economics, University of Thessaly, 28th October Street, 78, 38333, Volos, Greece

\section{Purpose}

- This study provides a fresh insight into the examination of the comparison between multinationality and firm performance, measured through technical efficiency levels by overcoming methodological constraints and misunderstandings presented in earlier research.

\section{Design/methodology/approach}

- We estimate firms' efficiency levels in a production function-type framework through technical efficiency levels using nonparametric data envelopment analysis (DEA). We include firms from both developed and developing economies, from different national origins and with different sectoral characteristics, with a particular focus on knowledgeintensive business services (KIBS) and capital-intensive business services (CIBS).

\section{Findings}

- The study confirms for the case of KIBS the existence of the three-stage sigmoid (Sshaped) hypothesis between multinationality and firm performance measured through technical efficiency levels. Finally, the empirical findings reveal that CIBS exhibit only the first two stages, thus forming a ' $U$ '-shape relationship.

\section{Originality/value}


We propose the application of different firms' performance measurements, providing us with the ability to unpack a firms' managerial decision processes with regards to determining the optimised investment(s) in technology and research and development and with a particular focus on knowledge-intensive business services (KIBS) and capital-intensive business services (CIBS).

Keywords: management, data envelopment analysis (DEA), firm, performance, multinationality 


\section{Introduction}

The concept of productivity is the expected indicator of efficiency in any production-based system, yet the various levels of analysis used - individual, company, sector, discipline, region, national and international - are often subjected to different and differing interpretations. As a consequence, it is difficult to measure total production factors. Whilst a number of parametric and non-parametric approaches have been used to accommodate the complexity associated with measuring productivity, each has limitations and benefits. Regardless of the method adopted, the correct identification of input and output indicators is critical for the reliability of results. Approaches to capture and measure productivity are constrained by and are generally steeped in the thinking of the manufacturing era.

The centrality of measuring efficiency is grounded in the mathematical and industrial era mindset ('what can easily be counted'), which we acknowledge as being important, but we propose to offer a more neo-liberal approach that focuses on evaluating 'what really counts' and posits the importance of systemic economic theory rather than just mathematical theory. This is important to operations managers when focusing on productivity maximisation as examining the performance-multinationality relationships, given post-industrial economies' production systems, are now becoming intertwined with the knowledge, big data and information landscapes. Operations managers are directly responsible for contributing to their organisations' financial performance. Understanding the most optimised investment strategy possible, in order to obtain and leverage the benefits of Research and Development (R\&D) in terms of technology enabling internationalisation, is critical. We contend there comes a tipping point, when the costs outweigh the benefits after critical levels of intensity and diversity.

Measuring organisational performance tends to focus on stakeholders, heterogeneous products, market conditions, business impacts and the impact and effect of time on activity and performance. Operations managers have historically deployed commonly accepted measures and measuring protocols, such as intellectual property patents, yet despite the limitations and inaccuracies having been presented in the literature, each approach has been beset by epistemological, methodological and practical differences to date. 
Our conceptual premise is that there is a much-needed renewed ability to empirically compare the performance of firms in order to identify performance gaps and improvement opportunities. This article contributes to filling a gap in the literature and in practice by identifying appropriate measures and how they should be combined and used to measure different firms' performance comparatively. This will allow for more meaningful comparisons of the performance of different firms operating in different sectors and geographical regions.

Existing studies on capturing and measuring organisational performance (e.g. Chatha and Butt, 2015) operate from a transnational comparisons perspective. There is a consensus that a firm's internationalisation has a number of business, corporate and social advantages and that it leads to the improvement of its performance through organisational learning, market expansion, risk diversification, technological transfer and the reach and richness of the product and service offering, amongst many others (e.g. Johanson and Vahlne, 1977; Kogut, 1985; Porter, 1990; Kobrin, 1991; Dunning, 1993; Kotabe et al., 2002).

Contemporary empirical research that seeks to measure the impact of the degree of internationalisation on firm performance has been rather inconclusive - for example, Contractor et al. (2003) and Contractor (2007). However, despite the empirical evidence of the positive effect of internationalisation on firm performance, few early empirical studies provide evidence that internationalisation has no effect on firm performance (Buckley et al., 1997, 1984; Morck and Yeung, 1991). Other threads of research argue that internationalisation has either a positive or a negative linear relationship associated with a firm's performance. Studies have shown that there is a nonlinear relationship - a U- or an inverted U-shaped form. Specifically, a number of studies show that the connection between firm performance and the degree of multinationality can be linear (e.g. Grant, 1987; Grant et al., 1988). Yet, current thinking suggests that the relationship is U-shaped (Qian, 1997; Ruigrok and Wagner, 2003). There is also a school of thought that the relationship forms an inverted U-shaped relationship (e.g. Sullivan, 1994a, 1994b), but this work has not featured extensively in current conversations in the area. Contrary to previous findings, Contractor et al. (2003), Lu and Beamish (2004), Thomas and Eden (2004), and Contractor (2007) demonstrate that the relationship between firm performance and multinationality has three stages and resembles an S-shaped relationship. 
Contradictions exist in the limited literature available and, indeed, research findings are inconclusive, for several reasons. Firstly, a potential source of those conflicting results may be attributed to the a priori assumption concerning a functional form of the examined relationship when deploying parametric techniques. Secondly, the different methodological (econometric) frameworks adopted may be the potential source of those conflicting results given the ideological premise. Thirdly, the different datasets applied in those studies may be an extra source of ambiguity, particularly when involving differing time periods and different types of multinationals from different origins operating in different markets. Fourthly, in the empirical model adopted, the omitted variables may also affect the overall result and produce further inconclusive findings. Finally, the two variables used as proxies of multinational performance and the degree of internationalisation (DOI) can further cause researchers to find conflicting results.

An obvious challenge to the studies outlined relates to measure a firm's performance and their usage of univariate accounting ratios, such as return on assets (ROA), return on equity (ROE), sales growth, and Tobin's Q, amongst others. The area of measuring performance tends to be informed by partisan accounting methods, which adopt semi-scientific aspects at best. This semi-scientific approach is often an illusionary objective, short-term evaluation (Mouritsen et al., 2009). These partisan ratios do not capture the overall firm performance. Specifically, they do not capture the technical/operational firm performance (i.e. the process in which they transform their production inputs into outputs). Accountants have suggested an array of measures (recorded value, assessed value, earning potential, return on investment etc.), which reflect a disciplinary, historical, and current view of what constitutes performance. Operations managers offer a set of measures - stock value, functional value (what a user/consumer will pay) and esteem value (what the user perceives the brand value to be to them), replacement value, and so forth - which reflect how they perceive the world and which, when taken systemically, indicate a view of a firm's performance. Contemporary research in operations management and business evaluation indicates that these accounting ratios are not fit for purpose when seeking to measure a firm's 'true' performance (e.g. Mantere and Ketokivi, 2013; Steigenberger, 2014). 
Taking a systemic view of the literature, these inaccuracies may be the main sources that have led to conflicting results when examining the internationalisation and firm performance relationship, suggesting the methodology approaches used need to be widened and reframed.

Our research is different because it involves a renewed investigation of the performancemultinationality relationship by taking into account the above-mentioned critical issues and by providing supporting evidence for the validity of the three-stage theory of internationalisation, as proposed by Contractor et al. (2003). This is timely and is of benefit to managers and policymakers for several reasons. Unlike the individual accounting ratios, we propose the application of different performance measurements to provide the ability to capture a firm's managerial decision process, which reflects crucial aspects of organisational learning theory. We measure a firm's performance by estimating the firm's efficiency levels in a production function-type framework. Specifically, we measure such performance by estimating its technical efficiency levels using a nonparametric technique known as data envelopment analysis (DEA), occasionally called frontier analysis. DEA methodology is not new to the operations management literature (Bendoly et al., 2009; Singhal and Singhal, 2012) and has established itself as a credible methodological framework for evaluating and quantifying firm performance (Wu and Barnes, 2012; de Koster et al., 2009; Ramanathan, 2005; Leachman et al., 2005).

In contrast to earlier studies investigating the internationalisation-firm performance relationship using performance/accounting ratios, this paper extends and enriches our understanding of how firms' internationalisation levels of their operations affect their ability to efficiently transform their production inputs into outputs by evaluating the efficiency deviation (from the frontier) as the maximum equiproportional increase of all outputs allowed by the available inputs. This applied methodological approach tackles the problems highlighted by current studies on measuring firm performance (Mantere and Ketokivi, 2013; Steigenberger, 2014) by providing a comparison - almost a meta-analysis - which is based on benchmarking protocols. This, in turn, allows for the comparison between regression and non-regressionbased techniques, which we contend is a methodological step forward as it provides us with the flexibility of pre-specifying any functional form of the investigated relationship in advance. 
The work of Chen et al. (2015) supports our premise that the DEA approach enables managers to understand their firm performance and is a more robust and enriching method than simply relying on accounting and other financial ratios. The study by Assaf et al. (2012) is the one of the few examples of applying cost-efficiency measures when examining the effect of multinationality. This paper extends the work of Kathuria et al. (2008) and compliments the work of $\mathrm{Wu}$ and Barnes (2012), exploring partner performance in the supply chain and in logistics (Koster and Van Nus (2009). This paper also extends the work of Hsu et al. (2015) and their curvilinear U-shaped relationship curve, which demonstrates that the benefits of Research and Development (R\&D) for internationalisation will eventually outweigh the costs after critical levels of intensity and diversity, and which have enriched firm performance.

To enrich the debate on how to measure and evaluate a firm's performance and to offset earlier methodological issues, we deploy a new time-dependent conditional frontier model (Mastromarco and Simar, 2015), following the recent advances advocated by Bădin et al. (2012). In contrast to traditional DEA approaches (Window Analysis or Malmquist Productivity Index) handling multiple time periods (Cooper et al., 2007), the proposed probabilistic DEA framework adopted allows researchers and evaluators to capture in a dynamic framework (time-dependent) the effect of multinationality incorporating directly different time/period phenomena (e.g. the global financial crisis) into the performance measurement. As a result, the adopted model is able to address directly the estimation involved when examining the relationships between efficiency and performance via organisational learning (Assaf et al., 2012). Moreover, this approach provides several unique modelling advantages when examining directly the effect of multinationality, accommodating our measurement in both the firms' efficiency levels (technological catch-up) and technological disruptive changes (technological changes), which are the two key mechanisms that drive organisational performance improvement. Based on the traditional DEA methods when handling panel data (Window Analysis or Malmquist Productivity Index), the researcher needs to use a two stage-DEA estimation in order to reveal the effect of multinationality on the estimated efficiency /productivity measures. This is normally undertaken via a literature review by estimating, in the first stage, the efficiency/productivity estimates (via Window Analysis or Malmquist Productivity Index) and then, in a second stage, when these estimates are regressed on some environmental factors (in our case firms' multinationality levels). However, as has been demonstrated by Simar and Wilson $(2007,2011)$, this regression based approach imposes 
some unrealistic assumptions on the data-generating process producing, therefore, biased estimates of the examined effects. ${ }^{1}$ On the other hand, the work of Simar and Wilson (2011) and Bădin et al. (2012) suggests that the applied methodological framework adopted in this study and originally introduced by Cazals et al. (2002), and Daraio and Simar (2005, 2007a, 2007b), can overcome those misspecifications and allows researchers to examine the effect of the environmental factors (i.e. multinationality) on the shift of the frontier (technological change) and on the movements alongside the frontier (technological catch-up) without imposing any unrealistic assumptions on the data-generating process.

The intellectual contribution here relates to unpacking the notion that multinationality contributes to technological changes through know-how and know-what in order to bring about efficacy, effectiveness and efficiency in business practices with regard to the actuality and productivity levels of the firm. To date, there has been little research that adequately unpacks the relationship between multinationality and firms' technological changes.

The final contribution of this paper to operations managers is that our model is empirically informed via a comprehensive dataset, which extends the methodological shortcomings of earlier studies. The research sample comprises both developed and developing economies of different national origins, as well as different sectoral characteristics, with a particular focus on knowledge-intensive business services (KIBS) and capital-intensive business services (CIBS) rather than solely on manufacturing-based firms. ${ }^{2}$ As a proxy of firms' multinationality level, we are using the transnationality index (TNI) calculated by UNCTAD.

Having provided a synthesis of the current, yet scarce, conversations in the literature and suggesting why operations managers need to revisit this area of activity, the next section

\footnotetext{
${ }^{1}$ The main problem of the two-stage regression based DEA studies is that they pre-assume that the 'separability assumption' among the inputs/outputs and the control variables holds (Simar and Wilson, 2011). Based on this assumption, those studies unrealistically assume that the support of the inputs/outputs used to produce the DEA estimates does not depend on the environmental/control variables used in the second stage analysis.

${ }^{2}$ For the classification of multinational firms into KIBS, we have adopted the classification made by the Industry of Canada and the Business Development Bank of Canada, which are based on using the Standard Industrial Classification (SIC). The classifications can be downloaded from http://www23.statcan.gc.ca/imdbbmdi/document/2514_D2_T9_V1-eng.pdf.
} 
describes the data and methodology that have been developed. This is followed by the presentation of the empirical data, and finally, we conclude this article by outlining the managerial implications of our results.

\section{Data and methodology}

\subsection{Variable description}

In order to evaluate the interplay between the degree of multinationality and firm performance, we apply a sample of the world's top 100 non-financial firms, ranked according to the size of their foreign assets, ${ }^{3}$ from 2001 to $2012 .{ }^{4}$ The sample includes leading international firms from 21 countries and 29 industries. The sample's characteristics enable us to provide a more robust picture of the internationalisation-firm performance relationship, avoiding the more traditional sampling bias caused by estimating the relationship with a single country and/or a single industry (Contractor, 2007).

In Appendix 1, we list the firms, the selected industries, and the countries that we include in our sample strategy. Furthermore, we capture a firm's dynamic learning effect by covering a period of 11 years. We have collected the data from annual World Investment Reports, issued by UNCTAD. These reports include data from the largest transnational corporations from developed and developing countries.

The firm's multinationality level is measured through the TNI, which is calculated by UNCTAD. The TNI is a composite index that measures a firm's degree of internationalisation (DOI) and is calculated as the average of three ratios: foreign assets to total assets, foreign sales to total sales and foreign employment to total employment. Table 1 presents the descriptive statistics of the variables used.

[Table 1 about here]

\footnotetext{
${ }^{3}$ The dataset has been extracted from World Investment Reports, which are issued by UNCTAD. The data can be downloaded from http:/unctad.org/en/Pages/DIAE/World\%20Investment\%20Report/WIR-Series.aspx.

4 According to Dyson et al. (2001) and Sarkis (2007) the number of firms' used must be at least three times the sum of the inputs and outputs used in order for the DEA estimators to calculate meaningful efficiency scores. In our case we have a sample of 100 firms over 12 years and three variables acting as inputs/output.
} 


\subsection{Methodological approach}

As presented earlier, we have outlined the novelty of our approach in order to measure a firm's performance through its technical efficiency instead of individual accounting ratios. This proposed measurement is more suitable because it reveals the ability of management to utilize the firm's resources, threshold, and core competencies efficiently. Our premise is that a firm is technically efficient if it produces the maximum output from a given quantity of inputs, such as labour and capital. A firm's managerial efficiency is measured by deploying a wellestablished methodological approach known as DEA. DEA is a mathematical programming technique that estimates the relative efficiency of production units and identifies best-practice frontiers. DEA, which was initially introduced by Charnes et al. (1978), encompasses the construction of a nonparametric piece-wise surface (i.e. the empirical frontier) over the examined data. Scores equal to 1 are indicated as being technically efficient, whereas if a firm has a technically efficient value of less than 1, this suggests that the firm is technically inefficient. ${ }^{5}$ Furthermore, following Daouia and Simar (2007), we also apply robust frontiers (known as Order- $\alpha$ frontiers) in order to be able to evaluate the effect of multinationality on firms, taking into account the extremes and outliers in our data. When applying robust frontiers, technically efficient firms can take values of their efficiency scores greater/equal to 1, whereas the technically inefficient firms take values of less than 1 .

Based on developments of Bădin et al. (2012), we apply the most recent approach introduced by Mastromarco and Simar (2015) to calculate time-dependent conditional efficiency measurements for the full and robust frontiers (see Appendix 2 for details of the methodology adopted). In our case, the time-dependent conditional efficiency measures enable us to estimate firms' technical efficiency by taking into account both the effects of time and the firms' multinationality levels. ${ }^{6}$

The final stage of our analysis incorporates the methodological approach by Bădin et al. (2012), which allows researchers and evaluators to visualise the effect of time and multinationality on firm performance. Therefore, by regressing firms' multinationality levels (MULTI) and time

\footnotetext{
${ }^{5}$ For our frontier analysis, we apply output-oriented models. In our DEA setting, we allow for variable returns to scale (VRS) in order to capture potential firms' scale effects in our efficiency measurement (Banker et al., 1984).

${ }^{6}$ This implies that our estimated conditional efficiency scores, as presented in this study, are calculated based on the assumption that time and multinationality influence the boundary of the attainable set (Bădin et al., 2012).
} 
(YEAR) on the two ratios constructed from the full $(Q)$ and robust $\left(Q_{\alpha}\right)$ frontiers, ${ }^{7}$ we are able to account for the effects of time and multinationality on firms' estimated performances without assuming any functional relationship between the examined variables. Therefore, having a firm's $i$ at time $t$, we can estimate the following nonparametric regressions:

$$
\begin{aligned}
& Q_{i t}=m\left(\operatorname{TIME}_{t}, \operatorname{MULTI}_{i t}\right)+u_{i t}, \\
& Q_{\alpha, i t}=m\left(T_{I M E_{t}}, \operatorname{MULTI}_{i t}\right)+u_{i t} .
\end{aligned}
$$

Our first regression (equation 1) determines the effect of time and multinationality on a firm's boundary (i.e. we seek to detect any potential technological change that shifts the frontier of the firm). However, the second regression (equation 2) seeks to measure the effect of multinationality and time on the distribution of firms' efficiencies. ${ }^{8}$ An increasing regression line indicates a positive effect of multinationality and time on firms' technological changes (shifts on the frontier) and on the distribution of their efficiencies (technological catch-up).

\section{Empirical results}

Prior to presenting our analysis regarding firm efficiency and multinationality, we provide an overview of firms' mean and standard deviation (Std) values of the unconditional technical efficiency estimates for both the full (Subfigure 1a) and the partial frontiers (Subfigure 1b).

We observe that the mean original technical efficiency estimates (VRS-Mean) have increased over the years, whereas during the initiation of the global financial crisis (GFC) we can observe a high fluctuation (2007-2010) also indicated by a sudden increase in their efficiencies' standard deviation values (VRS-Std).

\footnotetext{
${ }^{7} Q$ is the ratio of the time-dependent conditional efficiency estimate to the original (unconditional) efficiency estimate constructed from the full frontiers, whereas $Q_{\alpha}$ is the ratio of the time-dependent conditional efficiency estimate to the original (unconditional) efficiency estimate constructed from the robust (Order- $\alpha$ ) frontier.

${ }^{8}$ Following Li and Racine (2007), we have used a local constant estimator, and for bandwidth selection, we have applied the least squares cross-validation criterion.
} 
The results also reveal a negative effect of GFC on multinational firms' efficiency levels after 2009. This was expected since, in our modelling, we use both domestic and foreign (i.e. the total) quantities of employees, of fixed assets and of sales, in order to calculate firms' efficiencies levels. Since the firms in our sample have a high foreign expansion, we observe this heterogeneity overall has a negative impact on their efficiency levels, this effect being apparent after rather than before 2009. When looking at subfigure $1 \mathrm{~b}$, the results are less sensitive to firms that act as potential outliers; however, again the fluctuation in the estimated performance measure during the period of GFC initiation can be clearly observed accompanied by a fluctuation in Order- $\alpha$ 's standard deviation values. In both cases, this fluctuation corresponds to the outbreak of the global financial crisis. An increase in the volatility of a firm's performance reveals distortions in firms' technical efficiency.

[Figure 1 about here]

Figure 2 illustrates the effect of time and multinationality on firms' efficiency levels and technological changes. Specifically, subfigures $2 a, 2 c$ and $2 \mathrm{e}$ examine the effect of time and multinationality on firms' technological change levels (shift of the frontier), whereas subfigures $2 \mathrm{~b}, 2 \mathrm{~d}$ and $2 \mathrm{f}$ examine the effect on firms' technological catch-up levels (movements towards and away from the frontier).

By focusing on subfigure $2 a$ (which examines the entire sample), we can verify the three-stage sigmoid (S-shaped) hypothesis, as introduced by Contractor et al. (2003) and further discussed in Contractor (2007), suggesting that firms in their initial stage of internationalisation - that is, up to the $40 \%$ level - fail to have any technological change gains due to the barriers associated with their international expansion.

Once a firm overcomes this initial stage of multinationality - that is, from $40 \%$ to $85 \%$ - the effect becomes positive. This implies technological change gains due to the benefits linked with firms' international expansion. Finally, for a higher degree of multinationality - that is, greater than $85 \%$ - the effect of multinationality on firms' technological change levels is negative. The effect of time is positive, up to the initiation of the GFC. However, after this point it becomes negative, suggesting that the GFC affected negatively firms' ability to explore technological change gains. 
Subfigure $2 \mathrm{~b}$ examines the effect of multinationality and time on firms' distribution of technical efficiency levels (technological catch-up) for the entire sample. Also, the results in this case support the three-stage sigmoid (S-shaped) hypothesis. It is evident that, in the initial stage of internationalisation - that is, up to the $40 \%$ level, firms failed to have any technical efficiency gains due to the costs and barriers associated with their international expansion. However, once a firm overcomes this initial stage of multinationality - that is, from $40 \%$ to $78 \%$ - the effect is positive. This indicates that firms are able to exploit technical efficiency gains due to the benefits linked with firms' international expansion. Finally, for a higher degree of multinationality - that is, greater than $78 \%$ - the effect of multinationality on firms' technical efficiency levels is negative. This means that firms were over-internationalised with increased global coordination and managerial costs (Contractor, 2007). The effect of time, as in the previous case, is positive up to the initiation of the GFC. However, after this period it appears that the GFC imposed extra barriers on firms' ability to explore catch-up gains.

As suggested by Dyson et al. (2001) and Sarkis (2007), for the results obtained by DEA to be meaningful, the homogeneity requirement must be met. In short, all the firms compared have similar operational environments when the efficiency estimates are measured and analysed. Even though we are comparing the largest multinationals, our sample contains firms from different sectors. Therefore, in order to test the robustness of our results and fulfil potential shortcomings regarding the homogeneity assumption, we followed Contractor et al.'s (2003) guidance of separating our sample into two sub-samples. The first sub-sample includes only firms from KIBS while the second sub-sample includes only firms from CIBS. It is evident from subfigures $2 \mathrm{c}, 2 \mathrm{~d}, 2 \mathrm{e}$ and $2 \mathrm{f}$ that the pattern of the overall effects of multinationality on firms' catch-up levels and from technological investments does differentiate whether the firms are KIBS or CIBS.

Deeper analysis reveals that for the case of KIBS, the three-stage sigmoid (S-shaped) hypothesis is verified both for the case of technological change (subfigure 2a) and for the case of catch-up (subfigure $2 b$ ). Both cases reveal that the gains for firms' technological change and technological catch-up levels decrease on the initial stages of multinationality (that is, up to the $40 \%$ level). However, for internationalisation levels of $40 \%$ to $80 \%$, the effect becomes 
positive, whereas for multinationality levels greater than $80 \%$ the effect becomes negative again.

In contrast to the case of CIBS, we can observe that the effect of multinationality on their technological change (subfigure 2e) and technological catch-up (subfigure 2f) levels forms a ' $U$ '-shape relationship. This, in turn, suggests that for the initial stages of international expansion firms face negative returns on their technological changes and technological catchup levels up to a certain multinationality level. However, after that point, firms experience positive returns. It is evident that, for CIBS, the turning points are different for exploiting technological change and technological catch-up gains. The results suggest that the catch-up gains from their multinational expansion come with lower levels of multinationality (45\% level) compared with the gains derived from their technological change (58\% level).

Finally, it is also evident that the performance of firms classified as KIBS increased over the years, being less affected by the GFC period, whereas the performance of firms classified as CIBS decreased over the same period, being more affected by the outbreak of the GFC.

[Figure 2 about here]

\section{Conclusions and managerial implications}

This study confirms the existence of the three-stage sigmoid (S-shaped) hypothesis between multinationality and a firm's performance when measured through technical efficiency levels. Despite the fact that we used a different way of measuring firm performance, we successfully validated the three-stage hypothesis of multinationality as introduced by Contractor et al. (2003). We further extended our analysis by providing, for the first time, evidence that the three-stage hypothesis is verified for the case of KIBS whereas a ' $U$ '-shaped relationship is revealed for CIBS. Moreover, we argue that the multinationality and firm performance relationship is nonlinear (Contractor et al., 2003).

We contend that firms do benefit from multinationality when the degree of internationalisation reaches the level of $80 \%$ for KIBS and when exhibiting 45\% (technological change) and 58\% 
(technological catch-up) for CIBS. Even though we used a different dataset, a different methodological framework and a different time period, our findings fully support Contractor et al. (2003), who reported similar results, suggesting that KIBS conform to all three stages of the sigmoid hypothesis whereas CIBS exhibit only the first two stages, thereby forming a ' $U$ 'shape relationship. We also, for the first time, quantified the degree of internationalisation that is needed to shift a production frontier due to the introduction of new technologies (in both sectors - KIBS and CIBS). The results show that capital-intensive firms' services do not require the same degree of multinationality as knowledge-based firms to maximise their technological catch-up and technological change levels.

R\&D based innovations are important for any firm and nation to develop in order to bounce forward, yet many face difficulties in strengthening performance, as there is a tipping point, as evidenced by our research, between investment and return. Indeed, many have seen little improvement in productivity performance in recent years despite the new opportunities offered by globalisation and new technologies, especially the information and communication technologies (ICT), which suggests a diminishing return exists from the investment and, as such, needs managing before this happens.

This research has multidimensional implications in terms of adopted managerial and business strategies. Firstly, multinationality has to be adopted as an integral managerial strategy that improves firm performance, as our research suggests performance can be enhanced through technology based investments. Secondly, we have verified previous findings suggesting the existence of different forms of the multinationality-performance relationship. We have confirmed that multinationality is effective, but managers face the problem of finding the optimal degree of multinationality due to a sigmoid type of internationality. Thirdly, the benefit of multinationality is not rapidly exhausted. This allows managers to adopt relatively aggressive strategies for achieving an appropriate level of multinationality. In other words, managers can afford to adopt a long-term expansion plan to ensure they contribute to the long term financial sustainability of the firm. A very gradual decline in firm performance after achieving the first stage of multinationality should lead to a change or reduction in the degree of multinationality. Our findings confirm that the decline is only a temporary event before reaching the second stage of multinationality, but knowing how and when is important for managers. Fourthly, managers face a critical decision related to the overexpansion of the firms' 
production processes. If managers are not able to have control or governance of this process, then the third stage will arise, and diminishing returns will appear (especially if the firm is knowledge based). The duration and the path of expansion are unique for every firm and are determined by the firm's internal and external factors.

Managers have to be aware, that the multinationality-performance relationship is a three-stage, dynamic process and that any operations management enhancement policies have to cope with contestation and bifurcations. Operations managers need to create and or enable space for interaction towards innovation to happen, but need to be aware of the tipping point to ensure a positive return.

Areas of further research allied to this work could be positioned around 'tentative governance' which allows the innovation endeavour to be open ended, continually evolving, reflexive and reversible in nature, or what we coin as 'being able to play in unstructured broken play' to encourage organisational performance, but being able to enact governance at the right time, at the right place to the right technological innovation to ensure maximisation of return and wellbeing to the firm.

Many questions remain. For example, what are the factors in the firm's environment that encourage such innovative activity? How is aggregate productivity influenced by the innovative activities of individual firms? This implies that studying overall productivity impact(s) requires an examination of aggregate data as well as the evidence surveyed here. Given the 'tipping point' effect, exploring the firms resilience, which is not new in itself, but is in this context, would also offer additional insights into how firms could re-establish performance productivity once they had entered the area of diminishing return and how can they bounce back and indeed bounce forward back to an enhanced state.

Finally, since Johnson and Kaplan (1987) published their key text, Relevance Lost: The Rise and Fall of Management Accounting, performance measurement has gained a new lease of life both in practice and research (Neely, 1999). Today, the ability to compare empirically the performance of firms, in order to identify performance gaps and improvement opportunities, is critical. This research contributes to filling a gap by identifying appropriate measures and how they should be combined and used to measure different firms' performance comparatively. In 
particular, our findings on what measures to use and how to use these measures will allow for more meaningful comparisons of the performance of different firms operating in different sectors and geographical regions. This suggests a move towards increased publication of "performance information" that is compatible, comparable and useful, and, as such, shows the need to revisit existing methodological approaches when unpacking a firms' managerial decision processes with regards to determining the optimised investments in technology and research and development with a particular focus on knowledge-intensive business services (KIBS) and capital-intensive business services (CIBS).

\section{Acknowledgments}

We would like to thank the anonymous reviewers for their constructive comments in the enhancement of this paper. 


\section{References}

1. Assaf, A., Barros, C.P., Josiassen, A., and Ratchford, B. (2012). Internationalization and performance of retail firms: A Bayesian dynamic model, Journal of Retailing, 88(2): 191205.

2. Bădin, L., Daraio, C., and Simar, L. (2010). Optimal bandwidth selection for conditional efficiency measures: a data-driven approach. European Journal of Operational Research, 201(2): 633-640.

3. Bădin, L., Daraio, C., and Simar, L. (2012). How to measure the impact of environmental factors in a nonparametric production model? European Journal of Operational Research, 223(3): 818-833.

4. Banker, R.D., Charnes, A., and Cooper W.W. (1984). Some models for estimating technical and scale inefficiencies in DEA, Management Science, 32: 1613-1627.

5. Buckley, P.J., Dunning, J.H., and Pearce, R.B. (1977). The influence of firm size, sector, nationality, and degree of multinationality in the growth and profitability of the world's largest firms, Weltwirtschaftliches Archiv, 114: 243-257.

6. Buckley, P.J., Dunning, J.H., and Pearce, R.B. (1984). An analysis of the growth and profitability of the world's largest firms: 1972 to 1977, Kyklos, 37: 3-26.

7. Cazals, C., Florens, J. and Simar, L. (2002). Nonparametric frontier estimation: a robust approach, Journal of Econometrics, 106(1): 1-25.

8. Charnes, A., Cooper W., and Rhodes E. (1978). Measuring the efficiency of decision making units, European Journal of Operational Research, 2: 429-444.

9. Chatha, K.A. and Butt, I. (2015) Themes of study in manufacturing strategy literature, International Journal of Operations \& Production Management, 35(4): 604-698. doi: http://dx.doi.org/10.1108/IJOPM-07-2013-0328

10. Chen, C.M., Delmas, M., and Liberman, M.B. (2015). Production frontier methodologies and efficiency as a performance measure in strategic management research, Strategic Management Journal, 36:19-36.

11. Contractor, F.J. (2007). Is international business good for companies? The evolutionary or multi-stage theory of internationalization vs. the transaction cost perspective, Management International Review, 47(3):453-475.

12. Contractor, F.J., Kundu, S.K., and Hsu, C.C. (2003). A three-stage theory of international expansion: The link between multinationality and performance in the service sector, Journal of International Business Studies, 34(1): 5-18. 
13. Daraio, C. and Simar, L. (2005). Introducing environmental variables in nonparametric frontier models: a probabilistic approach, Journal of Productivity Analysis, 24(1): 93-121.

14. Daraio, C. and Simar, L. (2007a). Advanced Robust and Nonparametric Methods in Efficiency Analysis: Methodology and Applications. Springer: New York.

15. Daraio, C. and Simar, L. (2007b). Conditional nonparametric frontier models for convex and non-convex technologies: a unifying approach, Journal of Productivity Analysis, 28(1): $13-321$.

16. Daouia, A. and Simar, L. (2007). Nonparametric efficiency analysis: A multivariate conditional quantile approach, Journal of Econometrics, 140(2): 375-400.

17. de Koster, M.B.M, Balk, B.M., and van Nus, W.T.I. (2009). On using DEA for benchmarking container terminals, International Journal of Operations \& Production Management, 29(11): 1140-1155.

18. Dunning, J.H. (1993). Multinational Enterprises and the Global Economy, AddisonWesley: Wokingham.

19. Hsu, C.H., Lien, Y.C., and Chen, H. (2015). R\&D internationalization and innovation performance, International Business Review, 24(2):187-195. doi:10.1016/j.ibusrev.2014.07.007

20. Johanson, J. and Vahlne, J.E. (1977). The internationalization process of the firm: A model of knowledge development and increasing foreign market commitments, Journal of International Business Studies, 8(1): 23-32.

21. Kathuria, R., Joshi, M.P., and Dellande, S. (2008). International growth strategies of service and manufacturing firms: The case of banking and chemical industries, International Journal of Operations \& Production Management, 28(10): 968-990.

22. Kobrin, S.J. (1991). An empirical analysis of the determinants of global integration, Strategic Management Journal, 12: 17-37.

23. Kogut, B. (1985) Designing global strategies: Profiting from operational flexibility, Sloan Management Review, 26: 27-38.

24. Kotabe, M., Srinivasan, S.S., and Aulakh, P.S. (2002) Multi-nationality and firm performance: The moderating role of $\mathrm{R} \& \mathrm{D}$ and marketing capabilities, Journal of International Business Studies, 33(1): 70-98.

25. Leachman, C., Pegels, C.C., and Shin, S.K. (2005). Manufacturing performance: Evaluation and determinants, International Journal of Operations \& Production Management, 25(9): 851-874. 
26. Li, Q. and Racine, J. (2007). Nonparametric Econometrics: Theory and Practice, Princeton University Press.

27. Lu, J. and Beamish, P. (2004). International diversification and firm performance: The Scurve hypothesis, Academy of Management Journal, 47(4): 598-609.

28. Mantere, S. and Ketokivi, M. (2013). Reasoning in organization science. Academy of Management Review 38(1): 70-89.

29. Mastromarco, C. and Simar, L. (2015). Effect of FDI and time on catching-up: New insights from a conditional nonparametric frontier analysis, Journal of Applied Econometrics, $30(5), 826-847$.

30. Morck, R. and Yeung, B. (1991). Why investors value multi-nationality, Journal of Business, 64(20): 165-187.

31. Mouritsen, J., Hansen, A., and Ørts Hansen, C. (2009). Short \& long translations: Management accounting calculations \& innovation management, Accounting, Organizations \& Society, (34): 738-754.

32. Navarro, P., Bromiley, P., and Sottile, P. (2010). Business cycle management and firm performance: Tying the empirical knot, Journal of Strategy and Management, 3(1): 50-71.

33. Neely, A. (1999). The performance measurement revolution: Why now and what next? International Journal of Operations \& Production Management, 19: 205-228.

34. Porter, M.E. (1990). The Competitive Advantage of Nations, The Free Press: New York.

35. Steigenberger, N. (2014). Only a matter of chance? How firm performance measurement impacts study results, European Management Journal, 32: 46-65.

36. Thomas, D. and Eden, L. (2004). What is the shape of the multinationality-performance relationship? Multinational Business Review, 12(1): 89-110.

37. Wu, C. and Barnes, D. (2012). A dynamic feedback model for partner selection in agile supply chains, International Journal of Operations \& Production Management, 32(1): 79103.

38. Grant, R.M. (1987). Multinationality and performance among British manufacturing companies, Journal of International Business Studies, 79-89.

39. Grant, R.M., Jammine, A.P., and Thomas, H. (1988). Diversity, diversification, and profitability among British manufacturing companies, 1972-1984, Academy of Management Journal, 31(4), 771-801.

40. Ruigrok, W. and Wagner, H. (2003). Internationalization and performance: An organizational learning perspective, MIR: Management International Review, 63-83. 
41. Qian, G. (1997). Assessing product-market diversification of US firms, MIR: Management International Review, 127-149.

42. Sullivan, D. (1994a). Measuring the degree of internationalization of a firm, Journal of International Business Studies, 325-342.

43. Sullivan, D. (1994b). The "threshold of internationalization:" Replication, extension, and reinterpretation, MIR: Management International Review, 165-86.

44. Cooper, W.W., Seiford, L.M., and Tone, K. (2007). Data Envelopment Analysis - A Comprehensive Text with Models, Applications, References, and DEA-Solver Software. Springer, Heidelberg.

45. Sarkis, J. (2007): Preparing your data for DEA. In: Zhu, J. Cook, (eds.): Modelling Data Irregularities and Structural Complexities in Data Envelopment Analysis. Springer, Heidelberg: $305-320$.

46. Simar, L. and Wilson, P.W. (2007). Estimation and inference in two-stage, semiparametric models of production processes, Journal of Econometrics, 136(1): 31-64.

47. Simar, L. and Wilson, P.W. (2011). Two-stage DEA: Caveat emptor, Journal of Productivity Analysis, 36(2): 205-218.

48. Bendoly, E., Rosenzweig, E.D., and Stratman, J.K. (2009). The efficient use of enterprise information for strategic advantage: A data envelopment analysis, Journal of Operations Management, 27(4), 310-323.

49. Singhal, K. and Singhal, J. (2012). Opportunities for developing the science of operations and supply-chain management, Journal of Operations Management, 30(3), 245-252.

50. Dyson, R.G., Allen, R., Camanho, A.S., Podinovski, V.V., Sarrico, C.S., and Shale, E.A. (2001). Pitfalls and protocols in DEA, European Journal of Operational Research, 132(2), $245-259$. 


\section{Appendix 1}

Appendix 1a: Firm names

ABB, Abbott Laboratories, AES Corporation, Alcan Inc., Alcoa, Anglo American, Astrazeneca Plc, BAE Systems Plc, BASF AG, Bayer AG, Bertelsmann, BHP Billiton Group, BMW AG, British American Tobacco Plc, British Petroleum Company Plc, Carrefour SA, Cemex SA, ChevronTexaco Corp., CITIC Group, Coca-Cola Company, Compagnie De SaintGobain SA, Conoco Inc., CRH Plc, Daimler Chrysler AG, Deutsche Post AG, Deutsche Telekom AG, Diageo Plc, Dow Chemical Company, E.On, Electricité De France, Endesa, ENI Group, ExxonMobil Corporation, Fiat Spa, Ford Motor Company, France Telecom, General Electric, General Motors, GlaxoSmithKline Plc, Hewlett-Packard, Hitachi Ltd., Holcim Agf, Honda Motor Co. Ltd., Hutchison Whampoa Ltd., Hyundai Motor Company, IBM, Inbev, Johnson \& Johnson, Kraft Foods Inc., Lafarge SA, LG Electronics Inc., Liberty Global Inc., Linde AG, LVmh Moët-Hennessy Louis Vuitton SA, Marubeni Corporation, Matsushita Electric Industrial Co. Ltd., McDonald's Corporation, Metro AG, Mitsubishi Corporation, Mitsui \& Co. Ltd., National Grid Transco, Nestlé SA, Nissan Motor Co. Ltd., Nokia, Novartis, Pernod Ricard SA, Petronas - Petroliam Nasional Bhd, Pfizer Inc., Philips Electronics, PinaultPrintemps Redoute SA, Procter \& Gamble, Renault SA, Repsol YPF SA, Rio Tinto Plc, Roche Group, Royal Dutch/Shell Group, RWE Group, Sabmiller Plc, Samsung Electronics Co. Ltd., Sanofi-Aventis, Siemens AG, Singtel Ltd., Sony Corporation, Statoil Asa, Suez, Telefonica SA, Thomson Corporation, Thyssenkrupp AG, Total Fina Elf, Toyota Motor Corporation, Unilever, United Technologies Corporation, Veolia Environment SA, Vivendi Universal, Vodafone, Volkswagen Group, Volvo AB, Wal-Mart Stores, WPP Group Plc, Xstrata Plc. 
Appendix 1b: Country of origin and industries of the examined firms

\begin{tabular}{|c|c|c|c|c|}
\hline Country & Number of firms & Industry & Classification & $\begin{array}{l}\text { Number of } \\
\text { firms }\end{array}$ \\
\hline Australia & 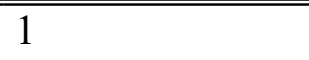 & Beverages & CIBS & 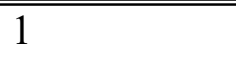 \\
\hline Canada & 2 & Business services & KIBS & 1 \\
\hline China & 1 & Chemicals & KIBS & 1 \\
\hline Finland & 1 & Construction materials & CIBS & 3 \\
\hline France & 14 & Consumer goods/brewers & CIBS & 2 \\
\hline Germany & 14 & Diversified & KIBS & 5 \\
\hline Hong Kong, China & 1 & Electrical and electronic equipment & KIBS & 10 \\
\hline Ireland & 1 & Electricity, gas, and water & CIBS & 7 \\
\hline Italy & 2 & Food, beverages, and tobacco & CIBS & 4 \\
\hline Japan & 9 & Industrial trucks, tractors, trailers, and stackers & CIBS & 1 \\
\hline Republic of Korea & 3 & Dealers of lumber and other building materials & CIBS & 1 \\
\hline Malaysia & 1 & Luxury goods & CIBS & 1 \\
\hline Mexico & 1 & Machinery and equipment & KIBS & 1 \\
\hline Netherlands & 2 & Media & KIBS & 1 \\
\hline Norway & 1 & Metal and metal products & CIBS & 3 \\
\hline Singapore & 1 & Mining and quarrying & CIBS & 4 \\
\hline Spain & 3 & Motor vehicles & KIBS & 13 \\
\hline Sweden & 1 & Non-metallic mineral products & CIBS & 1 \\
\hline Switzerland & 5 & Petroleum expl./ref./distr. & CIBS & 10 \\
\hline United Kingdom & 15 & Pharmaceuticals/chemicals & KIBS & 10 \\
\hline \multirow[t]{9}{*}{ United States } & 21 & Printing and publishing & CIBS & 1 \\
\hline & & Restaurants & CIBS & 1 \\
\hline & & Retail & CIBS & 4 \\
\hline & & Telecommunications & KIBS & 7 \\
\hline & & Tobacco & CIBS & 1 \\
\hline & & Transport and storage & CIBS & 1 \\
\hline & & Transport equipment & CIBS & 2 \\
\hline & & Water supply & CIBS & 1 \\
\hline & & Wholesale trade & CIBS & 2 \\
\hline
\end{tabular}


Appendix 2: Time-dependent conditional efficiency measures

Let multinational firm's production process characterized by the utilization of a set of inputs $X \in \mathbb{R}_{+}^{p}$ (in our case total employees and total fixed assets) into a set of outputs $Y \in \mathbb{R}_{+}^{q}$ (in our case total sales). Then let this process to be affected by environmental variables $Z \in \mathbb{R}_{+}^{d}$ (in our case the firms' multinationality levels). Then according to Cazals et al. (2002), Daraio and Simar (2005, 2007a, 2007b) and Bădin et al. (2012) the unconditional attainable set of the feasible inputs and outputs $\Phi=\left\{(x, y) \in \mathbb{R}_{+}^{p+q} \mid x\right.$ can produce $\left.y\right\}$ can be characterized by $\Phi=\left\{(x, y) \in \mathbb{R}_{+}^{p+q} \mid H_{X, Y}(x, y)>0\right\}$, where $H_{X, Y}(x, y)=\operatorname{Prob}(X \leq x, Y \geq y)$. Then the output oriented unconditional technical efficiency level of a firm operating at $(x, y)$ level can be defined as:

$\lambda(x, y)=\sup \{\lambda \mid(x, \lambda y) \in \Phi\}=\sup \left\{\lambda \mid S_{Y \mid X}(\lambda y \mid x)>0\right\}$.

As been introduced by Mastromarco and Simar (2015) let time $T$ as an additional conditioning variable (alongside with the environmental variable $Z$, introduced before) and for every time period $t$ of our analysis the attainable set can be redefined as $\Phi_{t}^{Z} \subset \mathbb{R}_{+}^{p+q}$ as the support of the conditional probability:

$H_{X, Y \mid Z}^{t}(x, y \mid z)=\operatorname{Prob}(X \leq x, Y \geq y \mid Z=z, T=t)$.

Then the conditional time-dependent output oriented technical efficiency measure of a multinational firm operating at $(x, y) \in \Phi_{t}^{Z}$ level at time $t$ facing the conditions $z$ can be defined as:

$$
\lambda_{t}(x, y \mid z)=\sup \left\{\lambda \mid(x, \lambda y) \in \Phi_{t}^{Z}\right\}=\sup \left\{\lambda \mid S_{Y \mid X, Z}^{t}(\lambda y \mid x, z)>0\right\},
$$

where $S_{Y \mid X, Z}^{t}(y \mid x, z)=\operatorname{Prob}(Y \geq y \mid X \leq x, Z=z, T=t)$.

Finally, by following Daouia and Simar (2007) the unconditional and the time-dependent conditional output oriented quantile (robust) efficiency measures for $\alpha \in(0,1)$ can be defined as: 


$$
\begin{aligned}
& \lambda_{\alpha}(x, y)=\sup \left\{\lambda \mid S_{Y \mid X}(\lambda y \mid x)>1-\alpha\right\} \\
& \lambda_{t, \alpha}(x, y \mid z)=\sup \left\{\lambda \mid S_{Y \mid X, Z}^{t}(\lambda y \mid x, z)>1-\alpha\right\}
\end{aligned}
$$

Given that we have a panel data of $\left(x_{i, t}, y_{i, t}, z_{i, t}\right)$ for $i=1, \ldots, n$ and $t=1, \ldots, s$ we can use the following DEA estimators in order to estimate the unconditional and conditional attainable sets. Assuming convexity and free disposability of inputs and outputs the DEA estimators for calculating A2.1 and A2.3 can be presented as:

$$
\begin{aligned}
& \widehat{\Phi}_{D E A, V R S}=\left\{\begin{array}{c}
(x, y) \in \mathbb{R}_{+}^{p} \times \mathbb{R}_{+}^{q} \mid y \leq \sum_{j=(i, t)} \omega_{j} y_{j} ; x \geq \sum_{j=(i, t)} \omega_{j} x_{j} ; \\
\omega \geq 0 \text { s.t. } \sum_{j=(i, t)} \omega_{j}=1
\end{array}\right\}, \\
& \widehat{\Phi}_{t, D E A, V R S}^{z}=\left\{\begin{array}{c}
(x, y) \in \mathbb{R}_{+}^{p} \times \mathbb{R}_{+}^{q} \mid y \leq \sum_{j \in \mathcal{J}(i, t)} \omega_{j} y_{j} ; x \geq \sum_{j \in \mathcal{J}(i, t)} \omega_{j} x_{j} ; \\
\omega \geq 0 \text { s.t. } \sum_{j \in \mathcal{J}(i, t)} \omega_{j}=1
\end{array}\right\},
\end{aligned}
$$

where $\mathcal{J}(i, t)=\left\{j=(i, v) \mid z-h_{z}<z_{i, v}<z+h_{z} ; t-h_{t}<v<t+h_{t}\right\}$ and $h_{z}, h_{t}$ are the appropriate bandwidths based on the data-driven method introduced by Bădin et al. (2010). For the additional unconditional and conditional estimators of the Order- $\alpha$ measures the interesting reader can follow the algorithms presented in Daouia and Simar (2007) and in Daraio and Simar (2007a). 


\begin{tabular}{|c|c|c|c|c|c|c|c|c|c|c|c|c|}
\hline & 2001 & 2002 & 2003 & 2004 & 2005 & 2006 & 2007 & 2008 & 2009 & 2010 & 2011 & 2012 \\
\hline & \multicolumn{12}{|c|}{ Total assets (in million US dollars) - Input } \\
\hline & 495210 & 575244. & 647483 & 750507. & 673342 & 697239. & 795337. & 797769. & 797769.0 & 751216 & 717242 & 685328 \\
\hline \multirow[t]{2}{*}{ Max } & 00 & 00 & 00 & 00 & 00 & 00 & 00 & 00 & 0 & 00 & 00 & 00 \\
\hline & 11066.0 & 11066.0 & 13976.0 & 16044.0 & 19013.0 & 20132.0 & 21288.0 & 21288.0 & & 21886.9 & 21886.9 & 21886.9 \\
\hline Min & 0 & 0 & 0 & 0 & 0 & 0 & 0 & 0 & 21886.93 & 3 & 3 & 3 \\
\hline Mea & 62929.4 & 68537.5 & 78278.6 & 86336.3 & 87842.7 & 92189.0 & 105088 & 105915 & 105859.3 & 113658 & 118277 & 121794. \\
\hline \multirow[t]{2}{*}{$n$} & 6 & 7 & 4 & 2 & 0 & 0 & 17 & 86 & 0 & 38 & 77 & 67 \\
\hline & 68207.8 & 76860.7 & 88189.5 & 98211.2 & 92415.5 & 88930.6 & 98416.9 & 99496.0 & & 99138.5 & 100398. & 106535. \\
\hline \multirow[t]{2}{*}{ Std } & 4 & 1 & 0 & 1 & 9 & 3 & 1 & 9 & 99523.51 & 4 & 34 & 21 \\
\hline & \multicolumn{12}{|c|}{ Total number of employees - Input } \\
\hline Max & 1383000 & 1400000 & 1500000 & 1710000 & 1800000 & 1910000 & 2055000 & 2100000 & 465000 & 2160800 & 2100000 & 2200000 \\
\hline Min & 13236 & 17684 & 17684 & 17684 & 17684 & 17684 & 3729 & 3856 & 9850 & 10374 & 10374 & 10374 \\
\hline \multicolumn{13}{|l|}{ Mea } \\
\hline $\mathrm{n}$ & 143450 & 141990 & 141021 & 143962 & 148182 & 151948 & 154134 & 158819 & 90618 & 151581 & 155156 & 158155 \\
\hline Std & 163521 & 164028 & 172248 & 189758 & 198188 & 209277 & 220993 & 225676 & 92740 & 230887 & 226350 & 235635 \\
\hline
\end{tabular}


217799. 244524. 256329. 291252. 358955. 365467. 390328. $459579 . \quad 2100000 . \quad 408085.470171 .467153$.

\begin{tabular}{|c|c|c|c|c|c|c|c|c|c|c|c|c|}
\hline Max & 00 & 00 & 00 & 00 & 00 & 00 & 00 & 00 & 00 & 00 & 00 & 00 \\
\hline Min & 4054.00 & 5151.00 & 5151.00 & 5151.00 & 5151.00 & 6413.00 & 7296.00 & 7296.00 & 3856.00 & 3856.00 & 3856.00 & 7296.00 \\
\hline Mea & 45854.0 & 47686.3 & 54105.7 & 59264.9 & 65466.4 & 69941.1 & 79840.1 & 83065.4 & 151149.7 & 83345.6 & 92044.3 & 88981.3 \\
\hline \multirow[t]{2}{*}{$\mathrm{n}$} & 9 & 7 & 6 & 8 & 4 & 0 & 1 & 4 & 9 & 5 & 7 & 5 \\
\hline & 44142.2 & 46909.0 & 52319.9 & 61702.8 & 68419.9 & 71899.0 & 75842.0 & 84500.9 & 224778.7 & 75600.3 & 89005.2 & 87615.9 \\
\hline \multirow[t]{2}{*}{ Std } & 6 & 3 & 2 & 3 & 9 & 5 & 8 & 8 & 0 & 9 & 7 & 0 \\
\hline & \multicolumn{12}{|c|}{ Degree of multinationality/TNI (percentage) - Exogenous variable } \\
\hline Max & 100.00 & 97.90 & 98.00 & 97.30 & 97.20 & 94.50 & 94.50 & 93.16 & 93.16 & 96.76 & 96.89 & 96.89 \\
\hline Min & 20.40 & 15.90 & 20.40 & 20.40 & 20.40 & 20.40 & 17.70 & 20.98 & 20.98 & 23.21 & 23.21 & 29.03 \\
\hline \multicolumn{13}{|l|}{ Mea } \\
\hline $\mathrm{n}$ & 58.08 & 56.86 & 57.66 & 59.05 & 59.74 & 60.78 & 62.23 & 62.38 & 62.36 & 63.88 & 65.14 & 66.30 \\
\hline Std & 19.83 & 19.22 & 18.33 & 18.01 & 17.12 & 16.66 & 16.58 & 16.51 & 16.58 & 17.08 & 17.15 & 15.69 \\
\hline
\end{tabular}

Table 1: Descriptive statistics of the variables 
Figure 1: Diachronic representation of firms' mean technical efficiency estimates

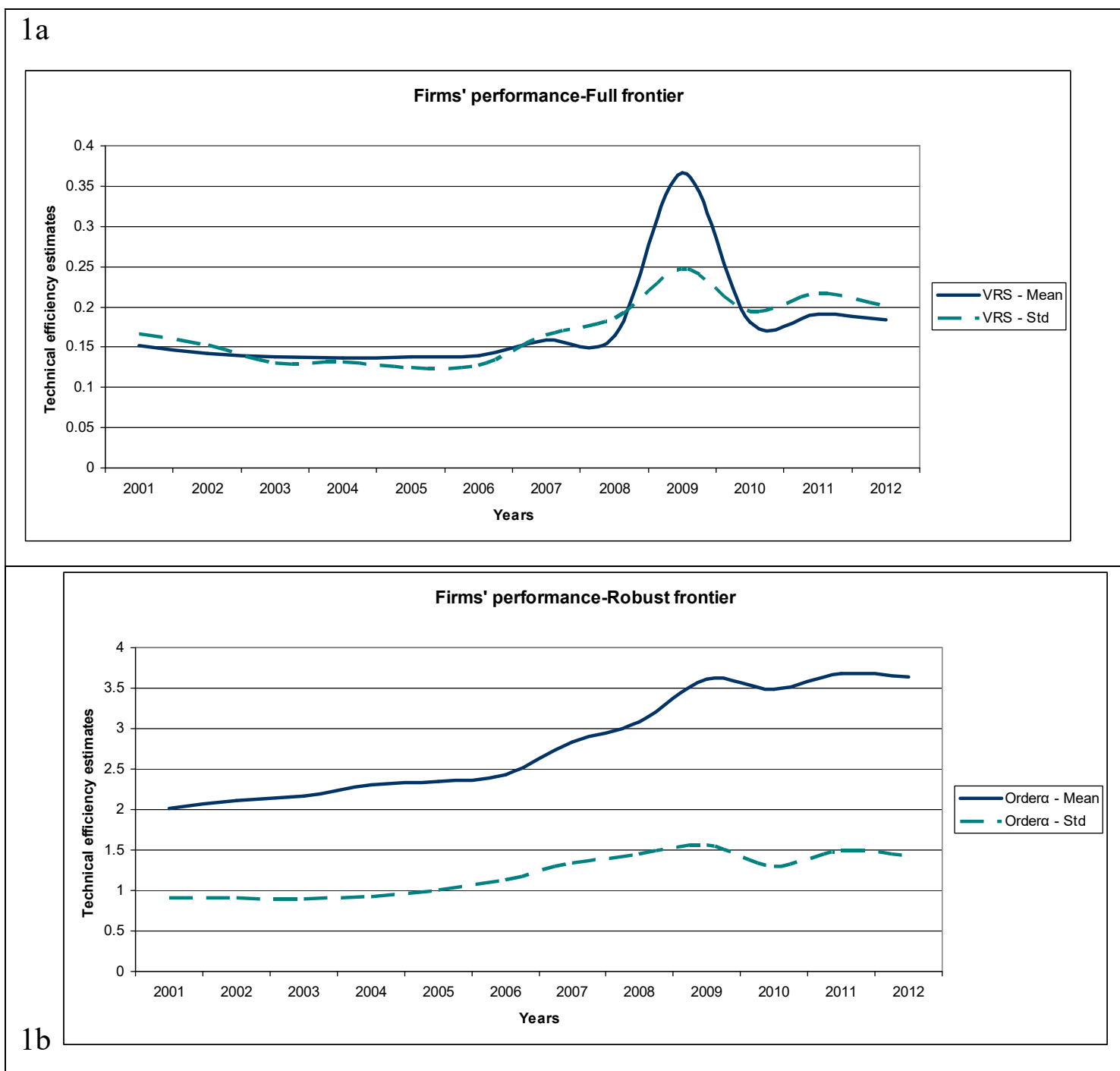


Figure 2: The effect of multinationality on firms' performance

The effect of 'Time' and 'Multinationality' on firms' technological change-All firms

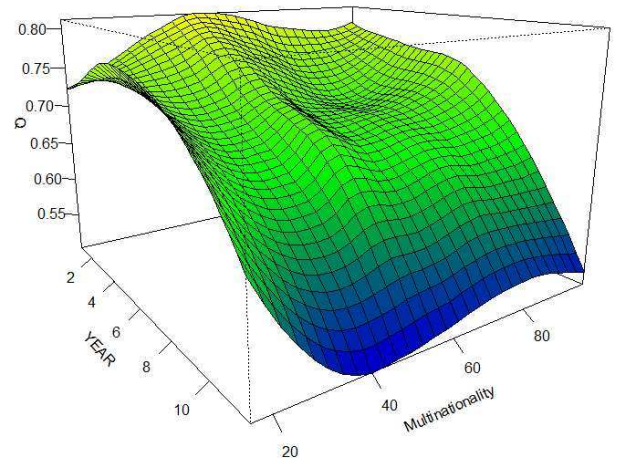

2c

The effect of 'Time' and 'Multinationality' on firms' technological change-KIBS

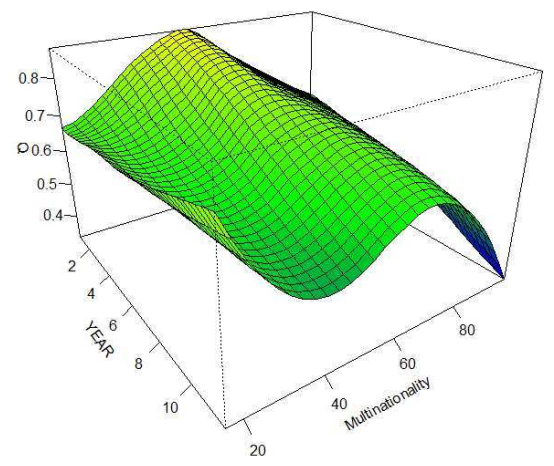

$2 \mathrm{e}$

The effect of 'Time' and 'Multinationality' on firms' technological change -CIBS

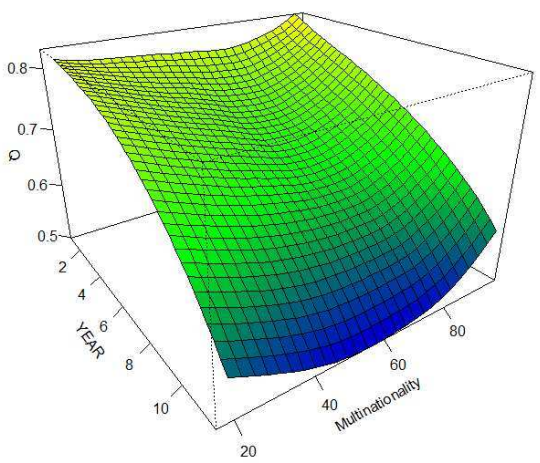

$2 f$

The effect of 'Time' and 'Multinationality' on firms' catch-up level -All firms

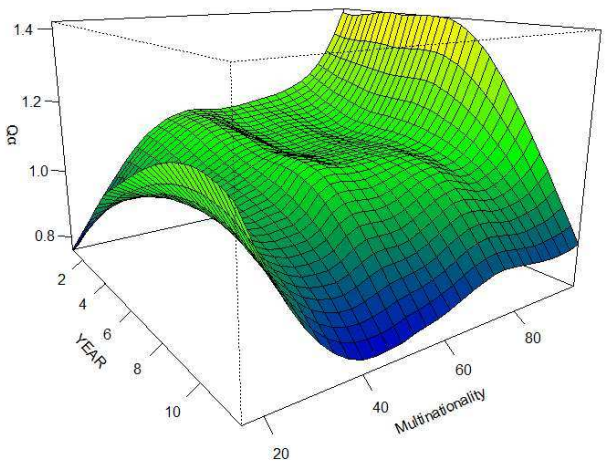

$2 d$

The effect of 'Time' and 'Multinationality' on firms' catch-up level-KIBS

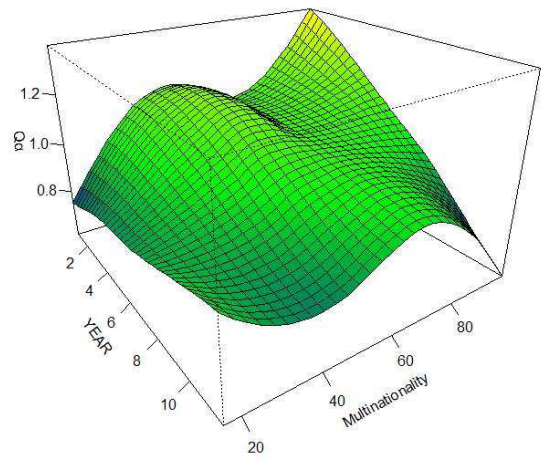

The effect of 'Time' and 'Multinationality' on firms' catch-up level-CIBS

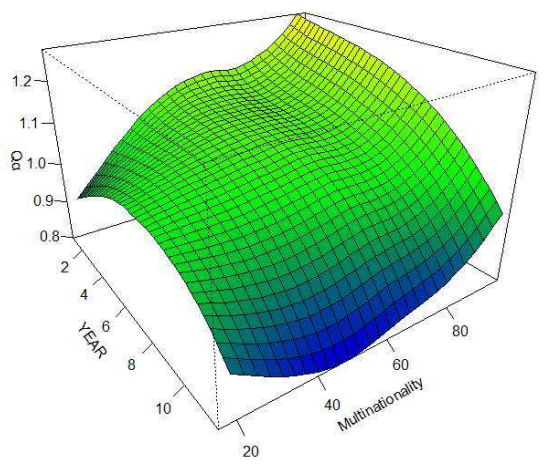

